\title{
ALIEN ABDUCTIONS: A RETURN TO THE MEDIEVAL
}

\section{Anthony Enns}

\section{The Return of the Repressed: Alien Sex and its Pagan Predecessors}

It is widely believed that the first alien abduction was reported by Barney and Betty Hill in New Hampshire in 1961. While driving along a mountain road one night, the couple witnessed a bright light which turned out to be a disk-shaped object. When the Hills reached their destination, they realized two hours had passed that they couldn't account for, and under hypnosis they told a detailed story about stopping at a roadblock manned by "short beings with large heads and eyes, small ears and mouths, and hairless ashen-colored skin" who took them aboard their alien ship and subjected them to unconventional medical examinations (Bynum 2).

This story has become the most familiar abduction scenario, and over the past four decades hundreds of similar stories have been reported by people from all over the world. It is a little known fact, however, that the first abduction was actually reported in Brazil in 1957 by a farmer named Antonio Villas Boas. Boas claimed he was working on his farm when a disk-shaped UFO landed and the alien crew dragged him inside and forced him to have intercourse with an alien woman. Although Boas' story is older, it is less frequently cited and the events it describes are less common to abduction narratives than those of the Hills'. For example, it is extremely rare for abductees to report being forced to have intercourse with alien women; most abduction narratives do not draw such an explicit connection between alien abduction and sexuality. Nevertheless, both these scenarios share a mutual concern with the manipulation and violation of the body, and whether it is explicit or not, the form this violation takes is clearly sexual.

The recurrence of details in the testimonies of abductees has been used to both defend and attack their validity. Believers claim that these similarities are themselves evidence that the narratives are true, while critics claim that abductees are simply appropriating images from the media to explain dream phenomena or hallucinations. An example of the latter is Joyce Bynum, who teaches folklore 
at San Francisco State University. Bynum believes that "abductees who lack a belief system may accept the extraterrestrial explanation from the popular media, merely because it gives them a way to express the incredible happening" (89).

Another possible source of material for these narratives is pagan mythology; Boas' account of molestation, for example, is similar to the myth of the succubus, a female demon who seduces men and extracts their sperm. However, the similarities between abduction narratives and pagan myths, like the similarities between individual testimonies, have also been used to both attack and defend the phenomenon. Critics claim that these similarities show that abduction narratives are no more true than Medieval demonic rape narratives, while abductees claim that they are proof that aliens have been conducting visitations for hundreds of years. There are several woodcuts from the 16th century, for example, which are believed to be evidence of UFO sightings (see Figures 1 and 2). One of the most outspoken abductees, novelist Whitley Strieber, also believes that pagan myths are evidence of alien abductions during the Middle Ages, but he adds a logical twist: "our ability to see and understand is literally distorted by the expectations that our cultures impose on us . . . [however] modern concepts about the nature of the visitors-when they are finally and completely formed-will be closer to reality than those of the past" (45-46). This idea-that we are closer to the truth than our pagan ancestors-is central to his distinction between modern visitations and those of the past: "that we could even conceive of having an objective relationship with this force is what is new about the visitor experience in modern times" (237).

Bynum accounts for the similarities between abduction narratives and folk tales by examining their modes of transmission: abduction stories have spread through our culture via popular media, just as folk tales spread via oral transmission. Bynum's theory might account for the widespread knowledge of these stories within their respective cultures, stories which could then be appropriated and retold, explaining why everyone was and is having the same experience. However, this theory cannot account for the similarities between folk tales and modern abduction narratives themselves because the two phenomena are obviously separated by hundreds of years. What is missing in this theory is an explanation of why medieval folk tales would reappear in the twentieth century as abduction narratives, which cannot be explained by looking at their modes of transmission alone.

Researchers on both sides of the debate agree that there are two possible explanations: either the planet is actually being invaded by a race of aliens who want to procreate with humans, or we are witnessing a widespread psychological phenomenon. Carl Sagan, for example, believes that a more probable cause of alien breeding paranoia is "the uneasy balance between sexual freedom and repression that has always characterized the human condition, and the fact that we live in a time fraught with numerous ghastly accounts, both true and false, of childhood sexual abuse" (5). There seems to be unanimous agreement that the stories concerning incubi, succubi, mares and vampires are all related to a common repression of sexual urges, but this is an approach that is not being 


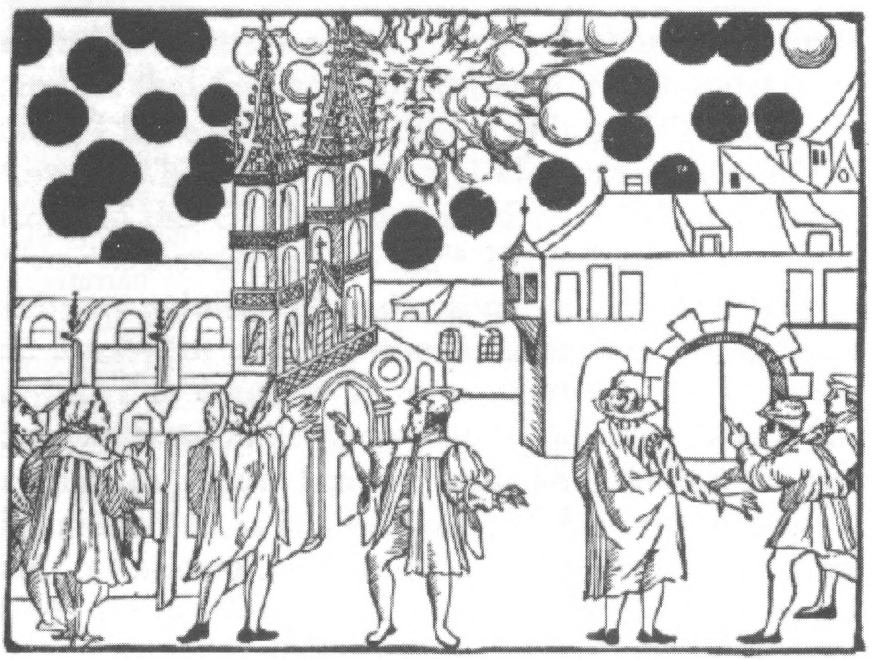

Figure 1: Objects allegedly observed over Basel, Switzerland, on August 7, 1566.

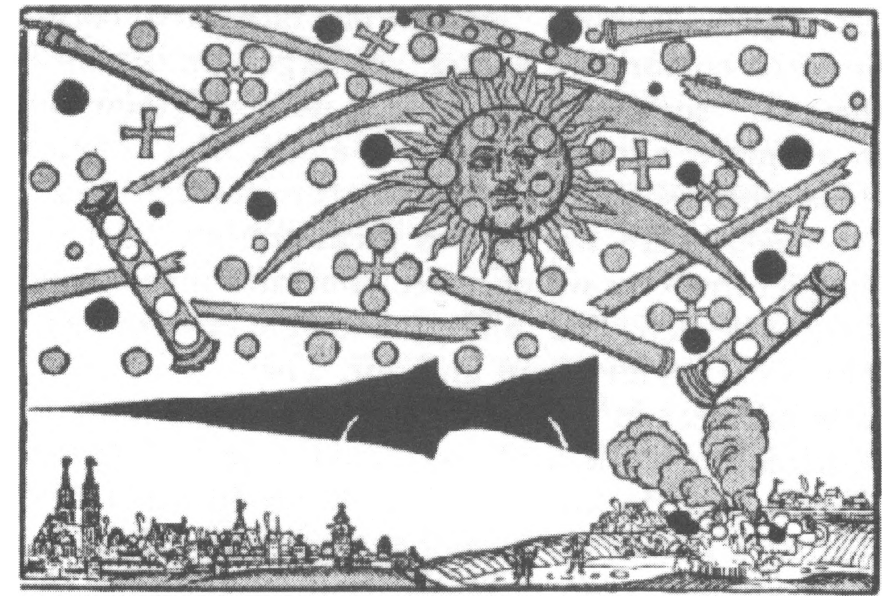

Figure 2: Unknown aerial phenomenon said to have flown in the skies of Nuremburg, Germany, on April 14, 1561. 
used in the treatment of abductees, a treatment which employs support groups, repressed memory therapy and hypnosis.

A comparison of Whitley Strieber's abduction narrative, Freud's case study of Dr. Schreber and Freud's essay on Christoph Haizmann's “demonological neurosis" will illustrate the similarities between the stories of an abductee, a paranoid psychotic and a man who claimed to have made a pact with the Devil. In each of these stories the subject created a projection of his repressed desire and this projection took a form which the subject adopted from his culture. Such a comparison will attempt to show that paranoid psychosis, pagan mythology and abduction narratives are all faces of the same psychological phenomenon, and that it is the interpretation of this phenomenon which has changed over time rather than the phenomenon itself. The crucial similarity between pagan myths and abduction narratives is that their respective cultures encouraged belief in their projections of repressed desire rather than their dissolution.

\section{Visitations on the Body: Demon Organs and Anal Probes}

In 1989, Thomas Bullard conducted a study comparing abduction narratives to folk tales. He found that abduction narratives, like initiations (narratives of supernatural kidnap and visits to the otherworld), contain eight episodes: capture, examination, conference, tour, otherworldly journey, theophany (encounter with a divine being), return and aftermath. And like these initiates, many abductees also report having apocalyptic visions and receiving messages about how to save the world from imminent disaster. Bynum also addresses the religious aspect of abduction narratives: "the stories of abductees have a religious element, since some believe they are special, that they have been given a chosen status to deliver messages, prophecies, and warnings from aliens to other human beings" (93).

Not only are the structures of folk tales and abduction narratives similar, but also an amazing number of visual details. For example, in 1645 a Cornish teenager named Anne Jeffries was found unconscious. When she was revived, she said that she had been assaulted by "little men." She had been unable to move as they took her up to their "castle in the air," where they molested her and then sent her home. She referred to these men as "fairies," and they continued to assault her regularly for a year until she was arrested for witchcraft.

Jeffries' account of little men and floating castles is identical to the accounts given by abductees of small, thin aliens and flying saucers, and the paralysis, molestation and recurring visitations are all common features of the abduction experience. But there are other, even more disturbing similarities between pagan myths and abduction narratives, such as the aliens' use of long needles inserted into the vagina, anus, navel or abdomen. Similarly, the penis of the incubi, a demon who visited women in their dreams and molested them, was said to be long, metallic, and "ice-cold." Rossell Robbins cites the testimony of Antide Colas, a witch who claimed that her incubus entered through a hole below her navel, and she had a scar there as evidence. 
Other similarities include the collection of eggs and semen and the insemination of women (supposedly for the purposes of creating a hybrid species). Thomas Aquinas was the first to document that "devils do indeed collect human semen" (Robbins 255). Aquinas believed that the succubus collected the semen and then transformed into an incubus, thus transferring the semen to a woman. This concept was supported for hundreds of years until Heinrich Kramer, in his Malleus Maleficarum (1486), described the incubus' ability to mate with women. (This idea reappears in the 17 th century in Fr. Sinistrari's De Daemonialitate et Incubis et Succubis.) In 1698, Johann Klein wrote a dissertation outlining the incubus' practice of stealing the babies who were produced from such unions. Similarly, many abductees claim to have given birth to human/alien hybrid children, who were then immediately stolen from them.

When abductees are asked whether they might not simply have been dreaming, they are always quick to reply that their abduction experiences were much more real than their dreams. The incubus was also thought to visit women during nightmares, but the experience was supposed to feel genuinely real. Charles Lamb described it as "a daylight vividness of vision that was all but being awake" (Robbins 356).

Another feature common to most abduction narratives is the feeling of being completely paralyzed while the event is taking place and of trying to scream or call for help but being unable to make a sound. Modern critics have tried to explain this experience as the naturally-occurring phenomenon of "sleep paralysis," in which the paralysis of sleepers is psychosomatic. In 1763, however, J. Bond described an identical paralysis in his book An Essay on the Incubus or Nightmare: "The nightmare generally seizes people sleeping on their backs, and often begins with frightful dreams ... and a total privation of voluntary motion" (Robbins 356). A similar account was also described by Richard Bovet in his book Pandaemonium (1684): "[The succubi] endeavored to come into the bed to him, being one on the one side, the other on the other side thereof, which he resisted with all the power he could ... they drew all the bedclothes off him ... he had no power to speak, or call for aid" (Robbins 357).

During the Middle Ages there was an ongoing debate concerning how spirits or demons could copulate with humans, as they were not believed to have physical bodies. Sinistrari, for example, claimed that "the devil assumes the corpse of another human being, male or female as the case may be, or, from the mixture of other materials, he shapes for himself a body, endowed with motion, by means of which he copulates with the human being" (Robbins 255). While abduction believers offer a different answer, it is curious that many of them are concerned with an identical question. John Mack, the Pulitzer Prize-winning Harvard Professor who has become famous for his belief in the validity of abduction experiences, has theorized that aliens exist in an alternate dimension which we cannot perceive. This concept-that the aliens do not possess physical bodies but are rather a non-corporeal consciousness-is echoed in the writings of Whitley Strieber, who believes that this is a possible explanation for their 
nocturnal visits and their attempts to communicate through dream imagery. Even for Strieber, however, the aliens do have a strong physical presence.

Many abduction narratives also include accounts of levitation; abductees often feel themselves levitating off their beds or being dragged up to the sky by a bright light. Strieber justified his own levitation experiences by citing examples from the stories of Catholic saints. St. Joseph of Cupertino was a saint in the 17 th century who supposedly levitated during mass, and St. Teresa of Avila was also known to levitate, which she described as a "great force" lifting her off the ground.

One of the most fascinating similarities between pagan myths and abduction narratives, however, is their method of investigation. Both narratives find their source in dreams or hallucinations and their victims believe that evidence for the reality of these experiences can be found on the body rather than in their memory. Many women in the Middle Ages, for example, did not report being seduced by incubi until after giving birth to babies; the babies were evidence of the reality of demonic visitations. Women also used accounts of visitation to explain the presence of burns and marks on the body, such as Antide Colas' abdominal scar. Most abduction scenarios are also interpreted through reading the body. For example, Budd Hopkins, one of the first and most well-known abduction researchers, conducts abduction support groups and private hypnosis sessions with abductees. He is known for telling people under hypnosis not to trust their minds or their conscious memory: "your body will remember."

An example of this practice of reading the body can be seen in the story of Leah Haley. Haley originally went to a therapist because she was having disturbing dreams. After undergoing hypnosis, her therapist told her these dreams were actually abduction experiences. Haley, however, did not find proof of her experiences in repressed memories but rather by looking to her own body: "Haley has found more than one hundred strange marks on different parts of her body, including injection marks, scoop marks, and red, circular vaccination like marks, apparently made with three separate prongs. She also reports other physical anomalies, such as Morse-Code-type beeps in her ears, intense back spasms, voices and imagery, and frequent soreness in her ovaries" (Rayl 60). Ronald K. Siegel, associate professor of psychiatry and biobehavioral sciences at UCLA, analyzed Haley's case. He noted that the brain responds in a finite number of ways to an infinite number of possible stimulations: "Abduction imagery is a manifestation of the limbic system, not outright insanity ... the aliens are not out there-they're in her own brain ... we all have the same details in our nervous system" (Rayl 88). This might account for both the similar experiences between abductees and their medieval counterparts: it is not the sensations which change over time, but rather the signifiers the experiencers project onto them.

\section{Revelations of Divine Intercourse: The Schreber Case}

"What can be more definite for a human being than what he has felt on his own body?"

-Daniel Paul Schreber 
A similar pattern can be seen in the narrative of Daniel Paul Schreber (18421911), who was the subject of one of Freud's most famous case studies. Schreber was the presiding judge of the Court of Appeals in Dresden in the kingdom of Saxony. For fourteen years he suffered from a severe mental illness that forced him to be hospitalized three times. After a visit from his wife during his second hospitalization, "he asked the attendant whether she had been a live person and, if so, whether she had stepped out of her grave" (Niederland 9). He believed that the Earth would last for only 200 years and that this allotted time had elapsed; he was the only man to have survived. He claimed that the people around him were not living, but rather they were "miracled-up" people, or “fleetingly-made little men." He believed he was receiving messages from God through rays of sunlight. First he developed a theory that Dr. Flechsig, his physician, was persecuting him and trying to "murder his soul," but he later revised his theory and decided that God was planning to murder his soul and use his body "like that of a whore." He believed he was transforming into a woman (what he called a growing "voluptuousness in my body"), that his penis was retracting into his abdomen, and after his second period of illness until the end of his life he was convinced that he had breasts and female genitalia. He was also convinced that he was the wife of God and that his union with God would produce offspring which would be the "source of a new mankind."

Schreber documented his illness in a journal which was published in 1903 under the title Memoirs. Freud never met Schreber, but he used this journal as the basis for his psychoanalytic evaluation. Freud surmised that the most important feature of Schreber's illness was his fantasy of emasculation. This was the key to understanding that Schreber's attitude towards his doctor, Flechsig, was actually produced by latent homosexual desire. Schreber's delusions of persecution were thus caused by his own psychological resistance to this desire. In his fantasy, Schreber then conflated Flechsig with God, which Freud interpreted as a conflict with his father, whom he loved. According to Freud, the climax of Schreber's delusion, when he believed that he had transformed into a woman and become the wife of God, showed that Schreber had taken his fear of being castrated by his father and turned it into the fulfillment of his homosexual desire. Therefore, Freud concluded, the root cause of paranoia among men was a "homosexual wishful fantasy of loving a man." He traced the forms this paranoia took as contradictions of the initial statement "I (a man) love him (a man)." This statement becomes "I do not love him-I hate him," a feeling which is then projected onto the beloved ("he hates me"), which is the source of the delusions of persecution ("Psychoanalytic Notes" 103-186).

According to William Niederland, this process of projection is crucial to an understanding of paranoia: "internal feelings, impulses, or ideas unacceptable to the ego are attributed to the environment; that is, something taking place within the patient enters consciousness as a disguised perception of the external world" (25). Niederland points out that paranoia is marked by three things: sexual conflict, fear, and the need for causality. The first two seem obvious, but 
the third may need some explanation. The paranoid subject's need for a chain of causality to explain his or her perceived experiences has the power of an "instinct." Niederland offers the example of the man who, under hypnosis, is given the order to go to the door and open an umbrella. When the man is released from hypnosis he obeys the order, even though the weather outside is pleasant. When asked why he opened the umbrella, the man immediately responds, "because it's raining." Niederland concludes: "the need for causality is so strong and urgent that, though the cause is lacking, it must in any case be supplied. It is invented" (33).

This invented cause seems entirely real to the subject, regardless of how illogical it might be. This clearly explains why Schreber believed his "miracles" were "incomprehensible, and at the same time concrete" (75). Lamb described a similar feeling of concreteness expressed by the victims of demon-nightmares, who experienced "a vividness of vision that was all but being awake." This same feeling of concreteness also appears in the accounts of abductees, and like these abductees, Schreber found evidence to prove the legitimacy of his paranoia by looking to his body: the retraction of his genitals, the removal of organs, the damage inflicted to his head, chest, abdomen and nerves, and what he called the "compression-of-the-chest-miracle . . . . It consisted in the whole chest wall being compressed, so that the state of oppression caused by the lack of breath was transmitted to my whole body" (76). This description is identical to one of the primary characteristics of incubi attacks, in which the victim feels "a heavy weight on the chest which interferes with breathing" (Robbins 356).

Another connection between Schreber's case and pagan myth is the recurring image of the vampire. Near the end of his second illness, Schreber claimed he was being attacked by vampires and demons. Merl Jackel links the idea of the vampire to the night Schreber experienced six nocturnal emissions. The fact that he was alone (his wife was on a four-day visit with her father) may account for an increase in his homosexual urges. Jackel concludes that Schreber's concept of "soul murder . . . meant submission to the male (Dr. Flechsig) at various levels of libidinal development" (Niederland 164). The vampire myth also echoes the abduction narrative in the theft of bodily fluid and the prevalence of anal probes in these narratives suggest submission to the male.

\section{Freud's "Demonological Neurosis": The Haizmann Case}

Like the Schreber case, Freud's analysis of Christoph Haizmann was based solely on texts (diaries and paintings preserved in a document known as the Trophaeum Mariano-Cellense); Haizmann himself had died more than two hundred years before. Haizmann was a painter who, after moving to Vienna in 1677, began to suffer from mysterious convulsions. The Prefect of the town, "suspecting some transaction with the Evil Spirit," induced Haizmann to confess that he had made a pact with the Devil, written in blood, which bound his soul for nine years. The Reverend Fathers of the town exorcised the Devil and Haizmann was released from demonic possession. He later returned in 1678, after another period of torment marked by convulsions, trances and visions, 
claiming that there was a second pact which needed to be annulled, and after this exorcism he joined the Order of the Brothers Hospitallers, where he died in 1700.

Freud often spoke of his interest in witchcraft and demonology, and he saw many of the concepts of psychoanalysis at work in medieval folk tales. His interest in analyzing Haizmann's case stemmed from a desire to show how these concepts were manifest in the narratives of demonology and how psychoanalysis could be performed on the remains of the past. The Trophaeum Mariano-Cellense contained a formal report by an Abbott describing Haizmann's exorcism, a preface written by a cleric, a deposition written by another Abbott, the painter's diary and a series of nine paintings which documented the ordeal. The most confusing part of the story concerned Haizmann's motive; he had rejected all the usual benefits of demonic pacts (money, power, sex). Freud's interpretation began with the fact that Haizmann's father had recently passed away and that Haizmann "had in consequence fallen into a state of melancholia" ("Demonological Neurosis" 81). The Devil, therefore, was a "father-substitute," as David Thurn explains: "The pact . . . was designed to provide the painter with a father-substitute in the hope that he might reclaim what he had lost" (856). Freud adds that the idea of the father as the model for both God and the Devil "has not been shown so clearly elsewhere" (87).

Haizmann's motive then becomes clear: like Schreber, Haizmann's Devil is the return of his repressed homosexual urges. Haizmann's neurosis also includes a transformation into a woman; Freud notes the nine-year period of the pact as a metaphor for pregnancy. This theory is complicated, however, by Haizmann's paintings of the Devil, in which he gradually develops breasts and transforms into a woman (see Figures 3 and 4). Freud claims that the Devil always appears as "a male, and, indeed, as a super-male, with horns, tail and a big penis-snake" (90), but that the presence of female characteristics indicates that Haizmann has projected his own femininity onto the father figure; the breasts thus symbolize "the child's tender feelings towards his mother" (90). Haizmann desires the father, but is unable to accept castration (transformation into a woman), so he "turned for help and salvation to the image of his mother" (91).

The Haizmann case resembles the Schreber case in other details as well. Haizmann's split of the father into God and Devil is analogous to Schreber's split of the father into low God and high God. This split, according to Thurn, is "generated by the fundamental ambivalence that governs infantile and primitive relations to the figure of the father and structures of the Oedipal complex" (858). There is also a similar focus on interpreting messages manifest in the body; Haizmann himself does not seem to understand that he is possessed by a demon until he has convulsions, trances and visions. And, like Schreber, there are similar undertones of vampirism: the pact with the Devil was written in blood, and thus the transaction can also be read as an exchange of bodily fluids. 


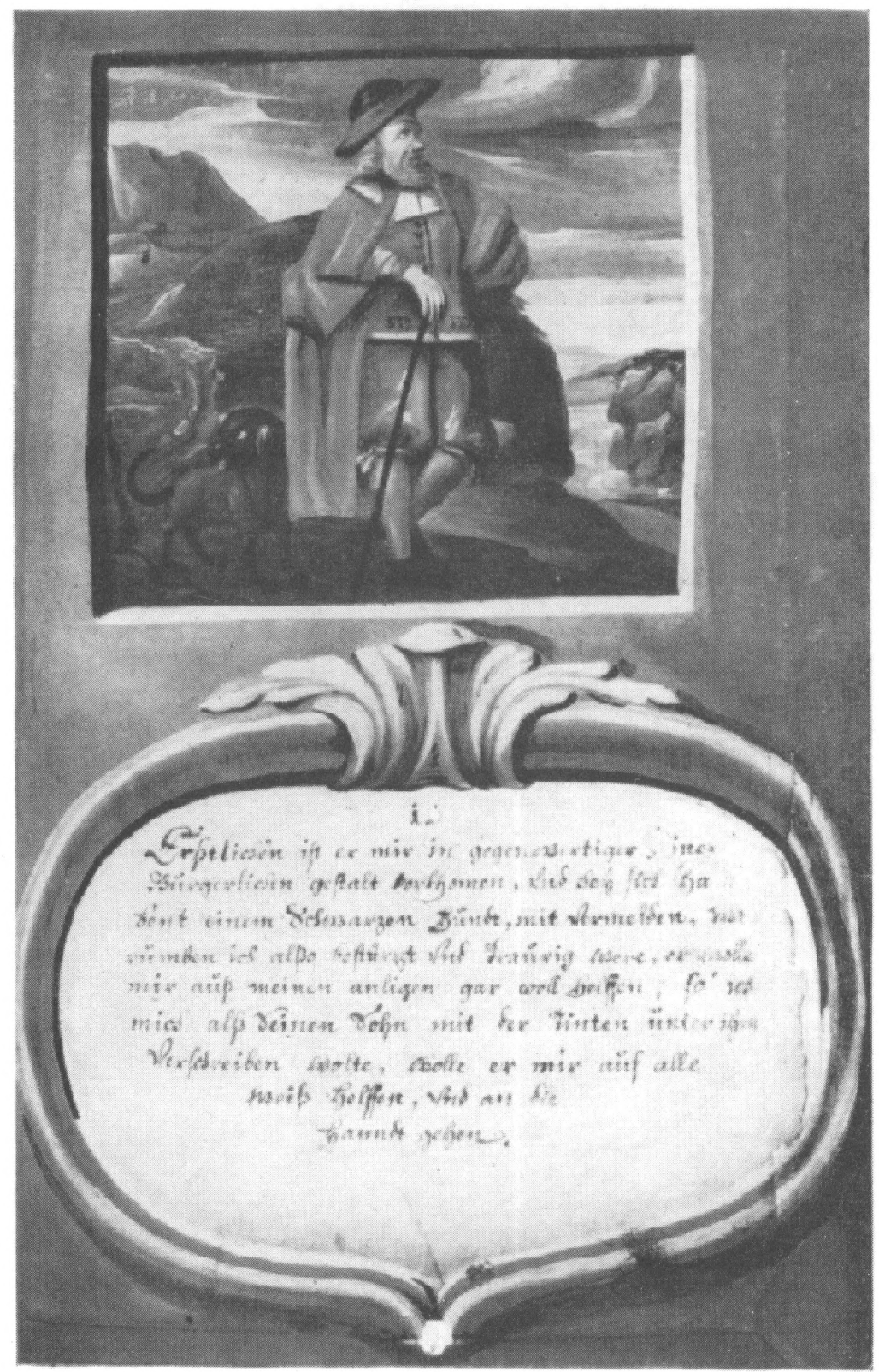

Figure 3: First appearance of the Devil to Christoph Haizmann. 


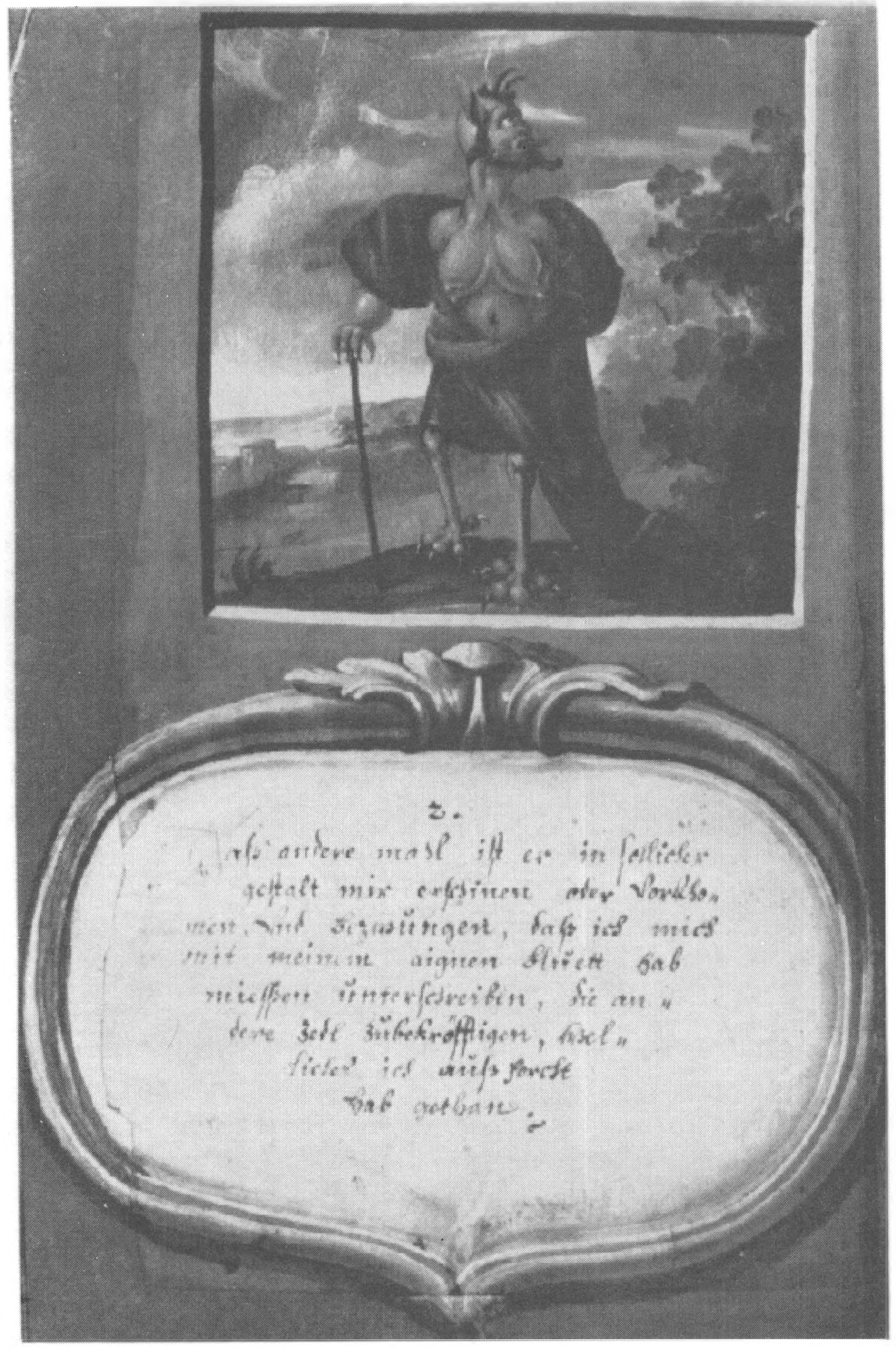

Figure 4: Second appearance of the Devil to Christoph Haizmann. 


\section{From Mortal Terror to Spiritual Love: The Strieber Case}

The connection between abduction narratives and pagan mythology can be most clearly seen in the work of Whitley Strieber, who is perhaps world's most famous alien abductee. In many ways, Strieber's narrative is significantly different from most abduction narratives: sexual molestation, anal probes and the theft of semen are all absent. Strieber is also unique in that he desires a relationship with his alien abductors, while in most narratives the aliens are depicted as extremely hostile. However, while it may not be representative of the average abduction experience, it is in some ways a proto-narrative: it is by far the most extensively documented, the most famous and possibly the most influential narrative due to its widespread exposure (his first book was even made into a film in 1990).

Strieber's first book, Communion (1986), is a personal account of his gradual realization that his nocturnal experiences were caused by recurring episodes of alien kidnapping, which began in his early childhood. Strieber's second book, Transformation (1988), charts his discovery of the aliens' motivation as well as a conversion in his attitude towards the aliens. In Strieber's early accounts of his abduction experiences, he stressed his sheer horror, his feelings of helplessness and a growing sense of paranoia, but from the earliest pages of his second book this fear was combined with a sudden desire for a relationship with the aliens. The aliens began to speak to him outside of their regular nocturnal visits, and Strieber became convinced that the aliens were imparting wisdom and knowledge to him. His fondness for them grew to the point where he wrote, "I loved them, wanted them, needed them, chose them, and called them . . . I was responsible for the visitor experience becoming a part of my life . . . I felt loved and cherished by something huge and warm" (140). The crucial moment in this conversion can be seen in the writings in his journal. He begins one entry with indecision: "I am thrilled by their power. Also, frightened. Curiously, I want them with me, to care about me. At the same time, I'm so darned scared" and ends with the discovery of the aliens' motivation: "Their function is in some way to make us evolve" (138). This evolutionary move involves discarding the physical body and becoming beings of pure consciousness. This passage is then followed by another entry in which Strieber longs for a relationship with his alien abductors/benefactors.

Strieber's desire for a relationship is not unlike Schreber's desire for a direct relationship with God; both are marked by a mixture of reverence and rebelliousness, shifting back and forth between feelings of love and delusions of persecution. These two memoirs are also similar in an astonishing number of details. Strieber even refers to a device the aliens use to draw the soul out of the body "with technology that may possibly involve the use of high-intensity magnetic fields" (240). This device is surprisingly similar to Schreber's notion of "soul murder." Both Schreber and Strieber are also subject to prohibitions: Schreber believes that God tells him not to masturbate, while Strieber believes he hears alien voices telling him not to eat sweets. It is also interesting to note that their relationships with their fathers were marked by conflict, and these 
fathers were both deceased at the time their delusions began, as was Haizmann's.

One of the most revealing similarities involves the pivotal night when Schreber was alone and his homosexual urges became so intense that he had six nocturnal emissions, after which he began to be contacted by supernatural forces and believed that Dr. Flechsig was plotting against him. There is an almost identical moment in Transformation where Strieber experiences an out of body experience (induced by aliens) which gives him "an explosive sexual reaction . . . My whole body was jolted by what I can only describe as a blast of pure sexual feeling" (191). He connects this feeling to death: "is death really a secret ecstasy?" (197). Strieber concludes this chapter with the following statement: "I had been allowed a glimpse between the worlds of the living and the dead" (202). This out-of-body experience, a vision of what Strieber calls the next "evolution" of mankind, is therefore marked by sexual ecstasy, which Strieber equates with the experience of death; a transgression of the boundary between the physical and the non-physical is therefore also a transgression of the boundary between the living and the dead. This evolutionary stage parallels Schreber's transformation into a woman; Strieber even refers to the sexually-nondescript aliens as possessing an aura of femininity. And the experience of being pulled outside of one's body becomes analogous to castration. With this in mind, the title Transformation suddenly takes on a definitely unintended significance: it does not suggest, as Strieber would have his readers believe, the actual transformation of his body from human to post-human, but rather the delusion of his transformation into a woman.

A more disturbing similarity between these narratives is a mutual vision of the apocalypse. In Communion, Strieber is convinced that the aliens have chosen him to impart a warning to the planet that they are in danger of destroying themselves from the damage done to the ozone layer. In Transformation, Strieber receives a more vivid message in the form of a vision in which the moon explodes and its fragments fall to Earth, destroying everything. He is convinced that this vision is a precognition and talks to several scientists to determine the possibility of such an occurrence. Like Schreber, Strieber's apocalyptic vision is also connected to his libido. According to Niederland, "Schreber's idea of ... the destruction of the world is the projection of this uncanny feeling of a devastating and pathological change within, caused by detachment of the libido from the representation of the external world" (25). A similar explanation could be applied to Strieber's moon explosion: it is a manifestation of the change occurring within him, his transformation into a feminine alien (a testicular explosion?), caused by the detachment of his homosexual urges with the outside world. And to make the comparison complete, both Strieber and Schreber see their transformations as the key to the salvation of the human race: for Strieber it is the hope of evolutionary advancement, and for Schreber it is the possibility of producing offspring with God that will result in a "new source of mankind."

A possible complication to this interpretation of Strieber's abduction narrative is that the principal alien who continues to appear in each of his abduction episodes, his father-substitute, possesses an obscure feminine quality. 
Considering Freud's analysis of the Haizmann case, however, this could also be interpreted as a projection of his own femininity onto the father.

\section{A Return to the Medieval: Enjoying Your Projection}

"Who watches us? It is a question that was once answered by the richness of mythology and faith. We have abandoned the mythology and lost the faith. The question must be addressed afresh, I suspect, if we are ever to understand our own true nature."

-Whitley Strieber

If there was any doubt as to the popularity of abduction narratives, it was quickly dispelled when Disney publicist Barbara Warren, promoting a one-hour television special, announced that alien abductions were real. Disney even added a new exhibit to Tomorrowland: "the ExtraTERRORestrial Alien Encounter." The phenomenon is so widespread that Michael Bershad, a man who claims to have been abducted in the early '70s, complained that he could no longer get any attention with his abduction narrative: "Now you have to have alien babies" (Vick A16). Indeed, the number of abductees has risen so dramatically that, according to the last Roper poll, two percent of Americans are being abducted regularly.

Carl Sagan has explained this recent phenomenon as an "epidemic of hallucinations" (5), but, in fact, these hallucinations, these projections of repressed desires, are extremely common and there is evidence of them at least as far back as the printed word. For believers, these hallucinations are very real, and they either spell the end of mankind or its next stage of evolution. For critics, they are merely manifestations of the limbic system or ways of inventing chains of causality for bodily experiences that defy explanation.

The real phenomenon of alien abductions is therefore not the stories of the abductees, but rather the way these narratives are being interpreted, or perhaps not interpreted. At the turn of this century these narratives would have been read and analyzed as texts which might reveal hidden layers of meaning, such as Schreber's Memoirs, but contemporary research seems to treat this phenomenon as if it was real. In his essay on the "demonological neurosis," Freud distinguished between the modern and medieval approaches to neurosis: "In our eyes, the demons are bad and reprehensible wishes, derivatives of instinctual impulses that have been repudiated and repressed. We merely eliminate the projection of these mental entities into the external world which the middle ages carried out" (72). The Middle Ages, it seems, was marked by an acceptance of these projections into the external world, an approach that is being practiced again today in the therapy of abductees, through support groups, repressed memory therapy, hypnosis, etc. It is unlikely that a contemporary abductee would be diagnosed as having latent homosexual urges, just as it would have been unlikely for Freud to have diagnosed such a patient as having been abducted by aliens. The mythology of witchcraft and demonology, which was rewritten in the last century through psychoanalysis, is being rewritten once again today. 


\section{Works Cited}

Bynum, Joyce. "Kidnapped by an Alien: Tales of UFO Abductions.” ETC.: A Review of General Semantics 50.1 (1993): 86-96.

Freud, Sigmund. "Psychoanalytic Notes Upon an Autobiographical Account of a Case of Paranoia (Dementia Paranoides)." Three Case Histories. Ed. Philip Rieff. New York: Collier Books, 1968. 103-186.

-. "A Seventeenth-Century Demonological Neurosis." The Standard Edition of the Complete Psychological Works of Sigmund Freud. 24 vols. Ed. and trans. James Strachey. London: Hogarth, 1964. Vol. 19. 72-105.

Niederland, William G. The Schreber Case: Psychoanalytic Profile of a Paranoid Personality. New York: Quadrangle, 1974.

Rayl, A. J. S. “Anatomy of an Abduction.” Omni 17.5 (1995): 60+.

Robbins, Rossell Hope. Encyclopedia of Witchcraft and Demonology. New York: Crown Publishers, Inc., 1960.

Sagan, Carl. “What's Really Going On?” Washington Post 7 Mar. 1993: WSP 4-7.

Strieber, Whitley. Transformation: The Breakthrough. New York: Beech Tree Books, 1988.

Thurn, David H. "Fideikommibbibliothek: Freud's 'Demonological Neurosis."” $M L N 108.5$ (1993): 849-875.

Vick, Karl. "UFO Abduction Tales Not Quite So Alien." Washington Post 19 May 1995: A1+. 